\title{
Radiative power of wildfires in Siberia on the basis of TERRA/Modis imagery processing
}

\author{
Evgenii I. Ponomarev
}

Siberian Branch of Russian Academy of Sciences, V.N. Sukachev Institute of Forest, Laboratory of Forest Monitoring, Akademgorodok 50/28, 660036 Krasnoyarsk, Russia, phone: +7 391 2494092, e-mail: evg@ksc.krasn.ru

\begin{abstract}
Variety of radiation power of wildfire was investigated by processing TERRA/Modis imagery in $4 \mu \mathrm{m}$ spectral band. Fire radiative power (FRP) was used for calibrating high-temperature event database obtained by the satellite technique. An analysis was performed on the database of Siberian wildfires for 2010-2012. Dynamics of FRP was investigated for a number of wildfires including some cases of crown fire. FRP variation was evaluated for various forest zones of Siberia. Classification of wildfires was elaborated in terms of FRP value as a GIS-layer over the territory of Siberia.
\end{abstract}

\section{KeY WORDS}

wildfire, radiative power, FRP, high-temperature event

\section{INTRODUCTION}

One of the main natural disturbances in boreal forests of Russia are wildfires. The annual area of wildfires is $2-17$ million ha in Siberian part of Russia (Conard et al. 2002; Soja et al. 2004; Shvidenko et al. 2011). An increase of wildfire activity and expansion of burned areas have been observed during last years (Loupian et al. 2006; Sukhinin 2008; Shvidenko et al. 2011; Ponomarev 2012). For example in 2012, there were over 23 thousand wildfires including 2200 large-scale ones within the area over $1500 \mathrm{ha}$. As a result, Siberian wildfires produced extreme emissions to the atmosphere in 2012 (Panov et al. 2012).

The use of satellite methods and products allowed to expand the area of monitoring, so as to increase the efficiency of wildfire detection, as well as to obtain more attributive information about wildfires, such as coordi- nates, estimation of active burning area, total damaged areas, temporal characteristics of fires, etc. These are especially important for northern territories of Siberia. The satellite technique is a primary means for wildfire monitoring in this region.

An important feature of multispectral satellite imagery usage is assessment of radiative energy of active fire. Information obtained is important for the analysis of fire impact on vegetation as well as assessment of emissions or forecast of post-fire conditions and regeneration dynamics.

In the present study, fire radiative power (FRP) was investigated by using methodology of $4 \mu \mathrm{m}$ TERRA/ Modis imagery processing (Kaufman et al. 1998).

The aim of the study was to analyze FRP variety for wildfires in Siberia and classify wildfire database records in terms of FRP value. 


\section{Area of investigation}

Russia is one of the biggest countries with forested territory, having about two-thirds of 1.2 billion ha of global boreal forests (FIRESCAN, 2013). A significant part of boreal forests is in Siberia. Siberia includes the territory of Asian part of Russia from the Ural Mountains up to the Far East.

The area of investigation contained a series of forest regions. In the west there is the Western Siberian plain swampy taiga; in the centre there are the Central-Siberian upland taiga regions and the Angara forest region; in the eastern part there are the Trans-Baikal mountain forest regions, the Pre-tundra forests of Eastern Siberia and the Permafrost taiga forest region of Eastern Siberia (see fig. 6 for details). The total area of observation was approximately 980 million ha.

\section{Material AND methods}

Characteristics of the process of burning in forests are highly variable and depend on a number of parameters such as forest and fuel type, average fuel load, weather conditions, duration of drying period, topography, etc. (Kurbatski and Sheshukov 1978). These factors determine a level of weather fire danger and a level of natural fire hazard (Nesterov 1949).

Fire intensity and burning rate of forest litter determine the type of wildfire. In boreal forests of Siberia up to $95 \%$ of fires are surface wildfires of low and moderate intensity and about $1-5 \%$ of overall fires are crown ones of high intensity (Kurbatski and Sheshukov 1978; Andreev and Brukhanov 2011; Ivanov et al. 2011).

The intensity of wildfires (low, medium and high) corresponds to power radiative flux from the active burning area. Based on subject literature, fire radiative power (FRP) can have a range $28-750 \mathrm{~kW} / \mathrm{m}^{2}$ per unit area of surface fire and depends on local environmental conditions and characteristics of forest fuel (Konev 1977; Valendik and Kosov 2008). Wide variety of fire radiative power was evaluated by means of experimental data on fire burning in Russian taiga and also in Canadian jack pine forests. There are estimates of the flux from fire edge in a range of $300-3200 \mathrm{~kW} / \mathrm{m}$ for surface fires, in a range of $4900-16700 \mathrm{~kW} / \mathrm{m}$ for intermittent/fully-developed crown fires along with extreme values in a range of 45200-54000 kW/m for some cases of crown fires (Korovin and Andreev 1988; Stocks and Hartley 1995).

The analysis of wildfire radiation power was carried out using surface brightness temperature from $4 \mu \mathrm{m}$ spectral band of TERRA/Modis imagery. The method and equation were proposed by Kaufman et al. (1998) (Justice et al. 2002):

$$
F R P=4.34 \times 10^{-19}\left(T_{4}^{8}-T_{4 b g}^{8}\right)
$$

where:

$T_{4}$ - brightness temperature of high-temperature pixel in $21^{\text {st }}$ channel of Modis radiometer $(\lambda=$ $3.989-3.929 \mu \mathrm{m}$ ),

$T_{4 b g}$ - the mean brightness temperature of background pixels.

An alternative FRP derivation was developed by Wooster et al. (2003), who normalized FRP over the area of integral flux (Mottram et al., 2005).

$$
\begin{gathered}
F R P=20.25 \times S \times\left(R_{4}-R_{4 b g}\right) \\
R=\sigma \cdot T^{4}
\end{gathered}
$$

where:

$R_{4}, R_{4 b g}$ - the radiance of high-temperature pixel and background pixels correspondingly to the Stefan-Boltzmann law, $\sigma=5,6704 \cdot 10^{-8} \mathrm{~W} /\left(\mathrm{m}^{2} \times \mathrm{K}^{4}\right)$ is the constant, $S \quad-$ remotely sensed area of active fire.

The unit of FRP measure is $\mathrm{W} / \mathrm{m}^{2}$ according to the equation (1). The dimension could be MW/pixel or MW when the equation (2) is used, which determines the integral characteristic per pixel of image. These dimensions are equivalent representation of the same characteristic. The last ones could be converted into $\mathrm{W} / \mathrm{m}^{2}$ and $\mathrm{W} / \mathrm{m}$ in compliance with spatial and linear characteristics of active fire, respectively. So, in the present study the unit of measure was used according to the equation (2).

For analyses we used own database of satellite detected wildfires for 2010-2012. It includes brightness temperature data as an attribute of daily observation of high-temperature events. Thus, a series of quick-looks was available for every wildfire during lifetime (fig. 1). We converted data into vector polygon layers for treatment in the geographic information system (GIS). 

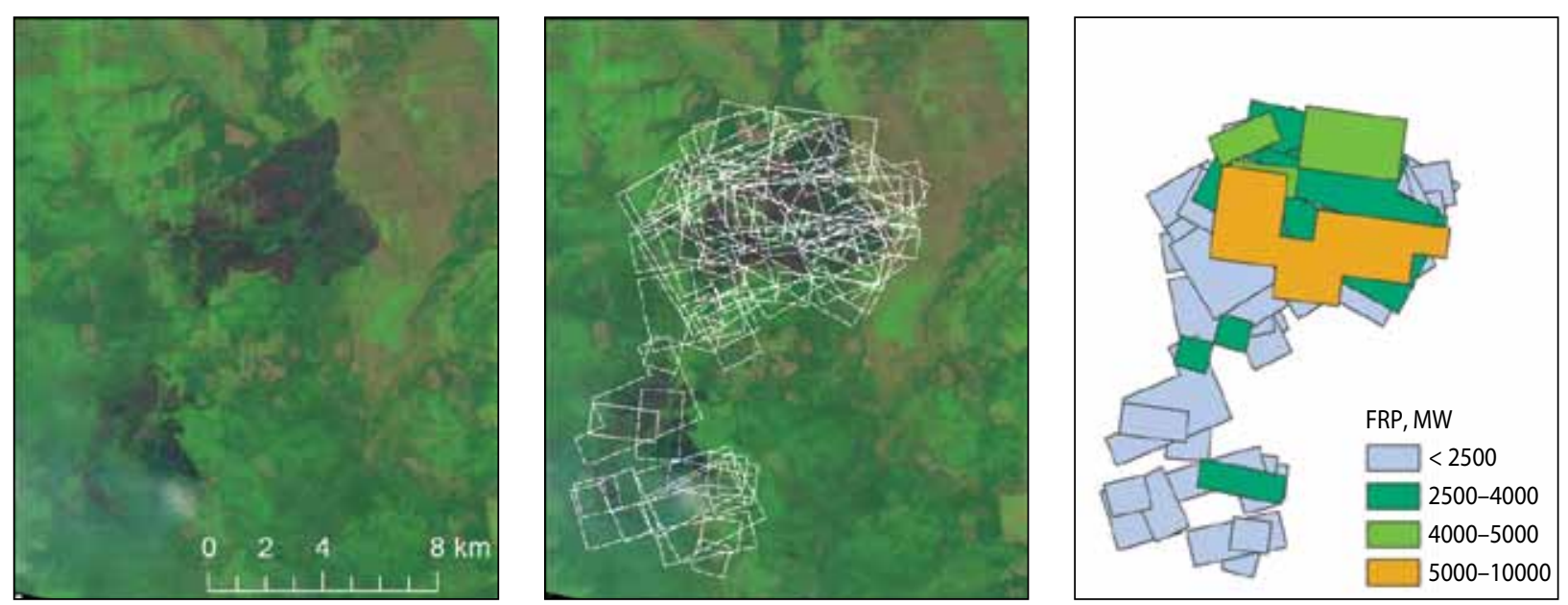

Fig. 1. Series of high-temperature events (white polygons) detected by TERRA/Modis over wildfire and the result of FRP classification. Landsat image of active fire is in the background

A

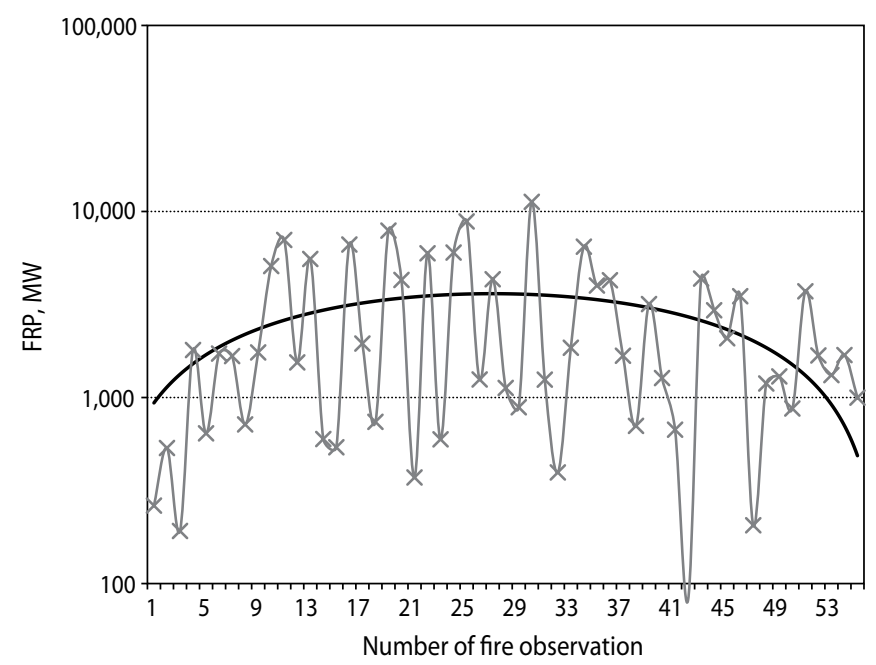

B

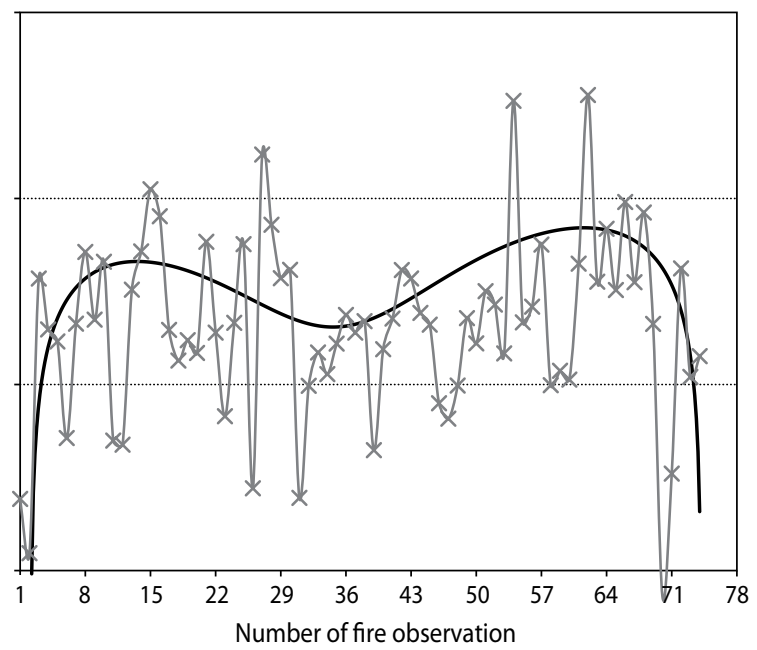

$*$ diurnal dynamics long-term component

Fig. 2. FRP dynamics of: A - surface fire of medium intensity, B - extreme values of FRP of crown fire

Results of daily satellite monitoring allowed getting up to 5-10 observations of active fire per day. FRP was calculated for every polygon of high-temperature event. Using this information daily and long-term dynamics of FRP was obtained (fig. 2) for different cases of wildfire. In total there were used more than $2.5 \times 10^{5}$ of calibrated high-temperature events per year.

We performed the conjugate geospatial analysis using GIS vector layers of wildfires calibrated according to FRP and vegetation maps of Siberia (Isachenko 1988; Bartalev et al. 2003).

FRP database was classified for different forest types: wildfires in pine (Pinus sylvestris) forests (more than 19000 high-temperature events per year), wildfires in larch (Larix) forests (30,000 high-temperature events per year), wildfires in Siberian pine (Pinus siberica) plantations (over 5000 high-temperature events per year), wildfires in deciduous forests (over 8000 high- 
temperature events per year), and burning non-forest areas (over 7000 high-temperature events per year). Histogram analysis procedure was performed for each of examined samples. Sporadic extremely high values of FRP or wrong data, (less than $1 \%$ of the total) were excluded. As a result, estimates of FRP variety were obtained for wildfires in forests dominated by pine, larch, Siberian pine and deciduous stands, as well as for fires at non-forest areas (meadows and agricultural land).

Furthermore, FRPs for wildfires under same environmental conditions were compared. The spatialtemporal filter in GIS was used. Forest fires were selected within the local area and during the same time. The area is located on the boundary of Central-Siberian upland taiga regions and the Angara forest region. It is dominated by pine plantations on burozem soil and larch and larch-pine stands on drained sod-podzol soils (Isachenko 1988; Isaev et al. 1994; Bartalev et al. 2003). Spatially wildfires were located within $35 \mathrm{~km}$.

Next, using GIS technology the FRP polygon layer was compared with distribution of crown fires that were recorded by the Russian Service of Ground and Air Forest Protection (Avialesookhrana). The comparison was carried out based on the spatial-temporal filter. So sampling series of calibrated high-temperature events were selected corresponding to Avialesookhrana crown wildfire records. Totally there were considered 73 crown fires that occurred in 2010-2012 in the Angara forest region in Siberia.

Finally, FRP ranges were marked out for different Siberian forest zones by means of the geospatial analysis in GIS. Thus the radiative heat flux from active fire is determined by zonal differences of local climatic conditions and by natural fire danger. Comparisons for different fire seasons were done as well.

\section{Results AND DISCUSSION}

Diurnal variation of FRP (fig. 2) was associated with stages of active fire spreading. The intensity of wildfire was rising at the noon local time (maximums of the curve) and was reducing at night and on early morning (minimums of the curve).

For wildfires over Siberia's territory, average FRP value was in range of 1200-4500 MW (fig. 3). The lowest value corresponded to burning of non-forest terri- tories. The mean value was $1900 \mathrm{MW}$ for wildfires in pine stands. The mean FRP for fires in larch stands was $3800 \mathrm{MW}$, which is twice of the flux of fire in pine forests. The average value of FRP was dropping down to $51-60 \%$ of the maximum during night-times. The same FRP reduction was found for the active fire in all types of tree stands, except for larch, where FRP value at night was not less than $80 \%$ of average for day-time.

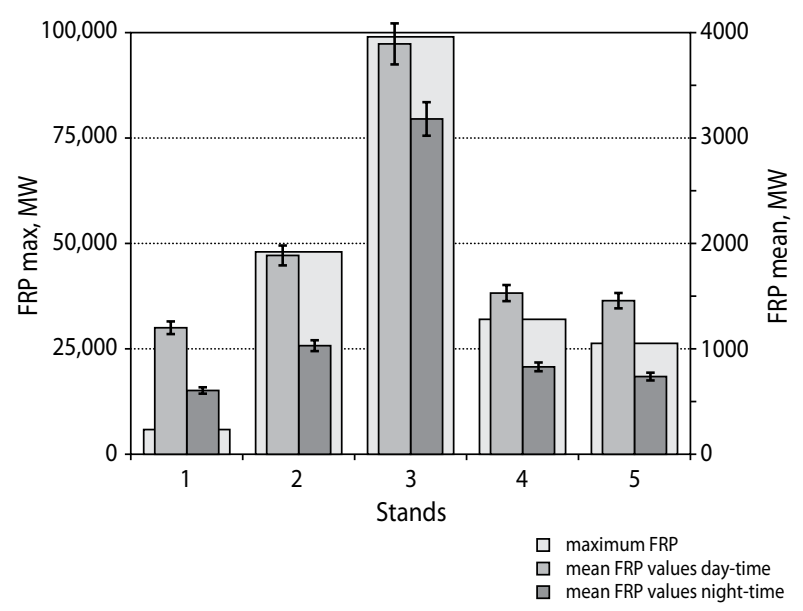

Fig. 3. Sporadic maximum and mean FRP values for the wildfire on territories dominated by: 1 - non-forest (meadows and agricultural lands), 2 - pine stands, 3 - larch stands, 4 - Siberian pine stands, 5 - deciduous stands

Extreme values of radiative power were marked out on the background of long-term and daily dynamics of FRP corresponding to high-intensity fires. Extremely high values of FRP were recorded in forests dominated by pine stands (up to $48000 \mathrm{MW}$ ) and larch stands (more than $90000 \mathrm{MW}$ ) (fig. 3).

The differences of FRP were mostly the same within local area under the same environment condition. FRP values depended on dominating tree stands. Examples of FRP series are presented for four fires operating simultaneously on the site in Central-Siberia taiga in July 2012 (fig. 4, fig. 6, inset).

Weather fire danger index PV-1 (Nesterov 1949) varied from 4600 to 8000 (weather station North-Enisejsk) during the time of observation. These values correspond to the fourth and fifth (the highest level) classes of weather fire danger. Thus, the intensity of burning as well as fire radiative power were determined mainly by fuel and dominating stands. 


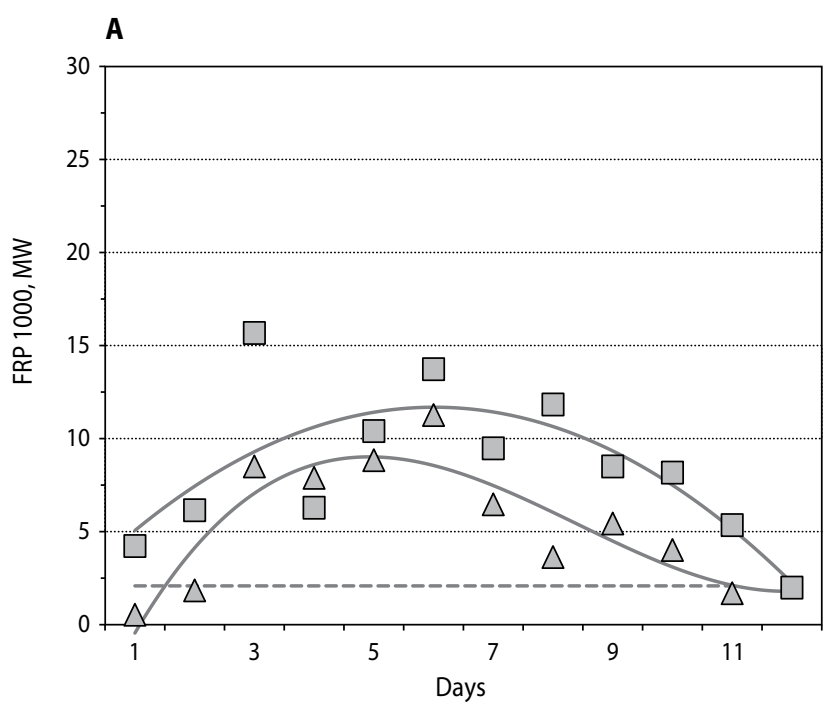

B

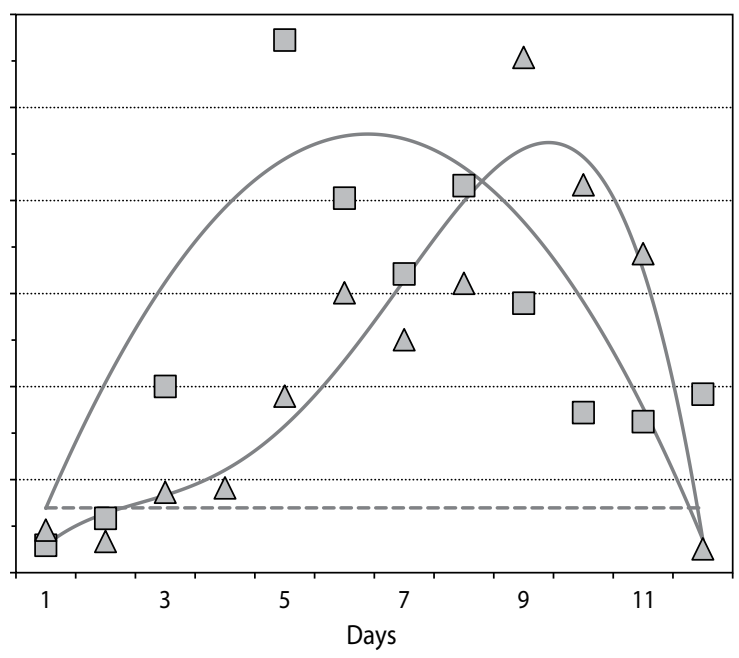

$\triangle$ maximum values per day

$\square \quad$ maximum values per day

-- mean FRP value per wildfire lifetime

Fig. 4. FRP dynamics for selected wildfires under same environmental conditions: $A$ - in pine stands, B - in larch and mixed larch-pine stands in Central Siberia taiga, July, 2012

FRP data were summarized daily during fire monitoring. Mean values were calculated for different times of active fire observations on the same day. Maximum values per day were used to plot a graph of fire flux dynamics during the period 20 July - 1 August 2012. So maximums of active fire intensity are presented in fig. 4. It was found that FRP of fires in larch stands (20,000-27,000 MW) was twice of that for fires in pines (10,000-12,000 MW). Qualitatively, the result confirms average distribution obtained for Siberia in total (fig. 3). And differences of FRP values in pine and larch stands were stored under high level of fire hazard. Thus remote sensed energy characteristics of active fires could be calibrated for classifying wildfire types in different tree stands.

The FRP maximums were analyzed for series of active fires in the stage of crown burning. Up to $95 \%$ of crown fires corresponded to extremely high FRP values. The latter exceeded average FRP up to 2-14 times (median $=4.6$ ). Thus, the proposed approach provided for accuracy of crown fires at a level 0.9-0.95. On the other hand, there are a number of limitations such as: satellite imagery may not be in the phase of wildfire maximum intensity, weather conditions and shooting conditions can introduce errors in accuracy of the brightness tem- perature and FRP calculating, the size of active burning zone is limiting significantly usage of satellite imagery with a resolution of $1000 \mathrm{~m}$.

We carried out regression analysis of crown wildfire FRP data versus the area of active burning. Groundbased data of the area were taken into account. The ratio did not depend on the fire season (fig. 5).

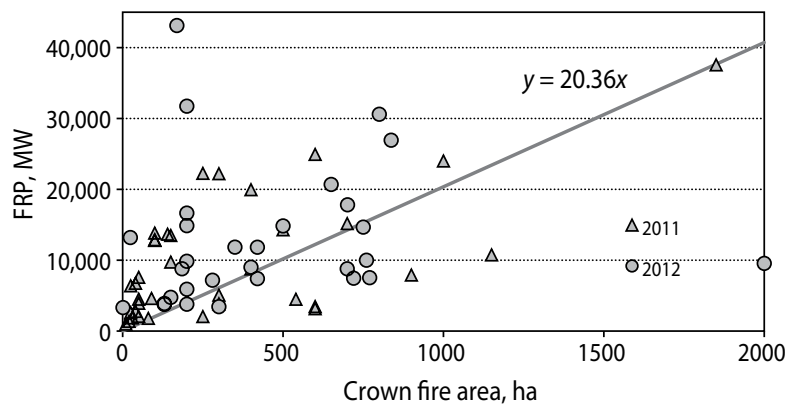

Fig. 5. Crown fire size ratio (according to ground-based data) and FRP for selected wildfires in the Angara forest region in 2011 and in 2012

Quantity of high-intensity wildfires was evaluated for the territory of Siberia. Percentage of high- and extreme-intensity wildfires could be used to deter- 
mine and to characterize the intensity of the fire season (tab. 1).

Tab. 1. Annual ratio of high-intensity wildfires in Siberia according to FRP range (\%)

\begin{tabular}{|c|c|c|c|c|}
\hline \multirow[b]{2}{*}{ Year } & \multicolumn{3}{|c|}{ FRP, MW } & \multirow{2}{*}{$\begin{array}{l}\text { Characteristic } \\
\text { of fire season } \\
\text { intensity }\end{array}$} \\
\hline & $\begin{array}{c}5,000- \\
-20,000\end{array}$ & $\begin{array}{r}20,000- \\
-35,000\end{array}$ & $>35,000$ & \\
\hline 2010 & 7.1 & 0.8 & 0.4 & Low \\
\hline 2011 & 18.7 & 2.9 & 1.0 & Medium \\
\hline 2012 & 29.8 & 7.7 & 2.8 & Extreme \\
\hline
\end{tabular}

The difference of FRP ranges appears at the scale of forest regions of Western, Central and Eastern parts of Siberia. Similar ranges of variation of FRP were recorded for the following regions: Pre-tundra forests and
Permafrost taiga forest region of Eastern Siberia (FRP $\max \sim 0.9 \pm 0.1 \times 10^{4} \mathrm{MW}, \mathrm{FRP}$ mean $\sim 4500 \pm 350$ MW), Western Siberian plain swampy taiga and CenterSiberian upland taiga (FRP $\max \sim 4.7 \pm 0.4 \times 10^{4} \mathrm{MW}$, FRP mean $\sim 1800 \pm 200 \mathrm{MW})$, Angara and the TransBaikal mountain forest (FRP $\max \sim 2.3 \pm 0.2 \times 10^{4} \mathrm{MW}$, FRP mean $\sim 2100 \pm 300 \mathrm{MW}$ ). The data for 2012 is presented at the map of forest areas of Siberia as classification of wildfires in terms of intensity (fig. 6).

The result obtained could constitute the basis for improvement of wildfire intensity forecasting. Data on FRP, weather conditions, forest region and predominant tree species need to be taken into account as well. The proposed approach is needed for quantitative and qualitative monitoring of wildfire causing emissions into the atmosphere (Sofiev et al., 2008; Panov et al. 2012; Yurova et al. 2013), as well as for assessing the global

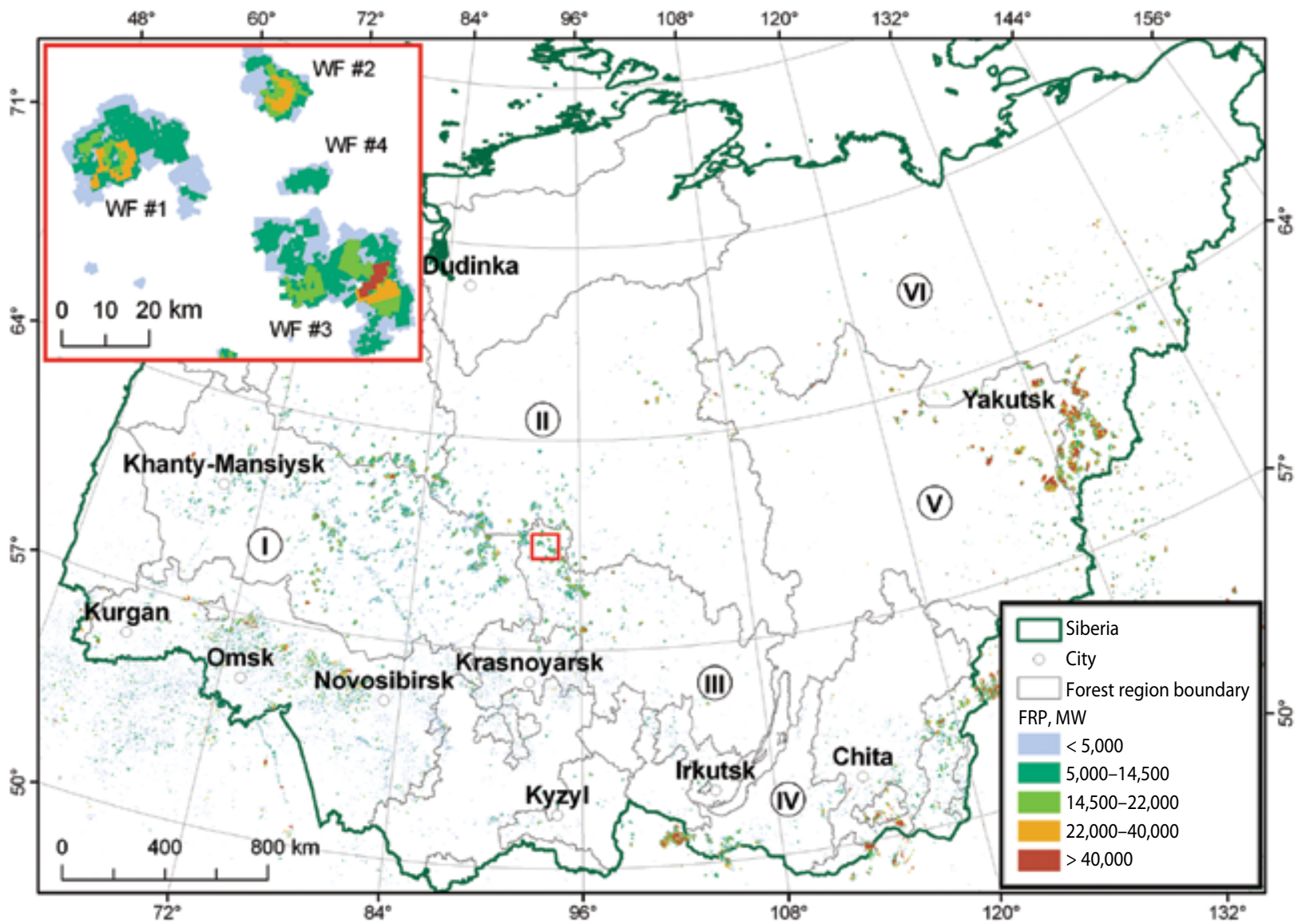

Fig. 6. Classification of 2012 wildfires in Siberia based on a FRP data. Forest regions of Siberia are: I - Western Siberian plain swampy taiga, II - Center-Siberian upland taiga regions, III - Angara forest region, IV - Trans-Baikal mountain forest regions, V - Permafrost taiga forest region of Eastern Siberia, VI - Pre-tundra forests of Eastern Siberia 
carbon budget. It is very important to improve reliability of fire role estimates by using qualitative characteristics of damaged areas and estimating burned biomass (Boschetti and Roy 2009; Kumar et al. 2011). Moreover, this is a new approach to assess vegetation disturbances after fire. Typically, this problem is solved by using the variation of vegetation index before and after the fire. However, remote data on FRP can be the basis for alternative estimating along with assessing the type and kind of fire, post-fire damages, and forecasting of vegetation recovering.

Thus, the use of the $4 \mu \mathrm{m}$ remote imagery followed by FRP calculation allows to classify forest fires as well as collect additional information on active fire dynamics. Raw data can be provided only by series of high-temperature events detecting for each case of forest fire by TERRA/Modis instrument or by an analogous technique.

Systematic research has not yet been carried out with the use of long-term database of forest fires in Siberia. However, the importance of this direction for the analysis of the fire situation in Siberia is unquestioned (Mottram et al. 2005; Berezin et al. 2013). Having the retrospective database of satellite detected wildfires for the period of 1996-2013, we expect to implement geospatial analysis for annual data, as well as to calibrate remote sensing measurements by ground-based experiments.

\section{Conclusions}

Remote sensing data in infrared range was used to estimate the power of the radiative flux from active fires in Siberian forests. The analysis of the FRP dynamics during the time of the fire lifetime was performed. There were recorded diurnal (up to $40-49 \%$ reducing in the FRP level) and long-term components that characterize changes in burning intensity during fire activity. Fires in larch forests were marked out for their diurnal variation of FRP which was not more than $20 \%$. It was found that against the background of the long-period and daily dynamics of FRP there may be sporadic extreme values corresponding to the case of crown fire ignition. The proposed approach provided for accuracy of crown fires at a level of 0.9-0.95.

The limits of FRP variation were determined for wildfires under different conditions and in different forest types. For fires in pine forests, FRP values were $10000-12000 \mathrm{MW}$, and up to $48000 \mathrm{MW}$ in the case of extreme heat radiation power. FRP values were 20000-27000 MW for wildfires in larch stands, with a sporadic - extremely high - value over $90000 \mathrm{MW}$. FRP characteristics can be used to determine the type of fire, burning intensity estimate, and also as characteristics of fire season intensity.

The classification of wildfires based on FRP values was made for Siberia territory. The result was presented in the format of vector polygon coverage for GIS. Similar ranges of variation of FRP values were recorded for the zones of Pre-tundra forests and Permafrost taiga forest region of Eastern Siberia, the Western Siberian plain swampy taiga and the Center-Siberian upland taiga regions; the Angara forest region and the TransBaikal mountain forest region.

\section{Acknowledgements}

The author gratefully acknowledge financial support for this research from the National Aeronautics and Space Administration (NASA) and from the Russian Foundation for Basic Research.

\section{References}

Andreev Yu.A., Brukhanov A.V. 2011. Prevention, monitoring and control of wildfires (for example, the Altai-Sayan Ecoregion): A Reference Guide (in Russian), Krasnoyarsk.

Bartalev S., Belward A., Erchov D.V., Isaev A.S. 2003. A new SPOT4-VEGETATION derived land cover map of Eurasia. International Journal of Remote Sensing, 24 (9), 1977-1982.

Berezin E.V., Konovalov I.B., Ciais P., Broquet G., Wu L., Beekmann M., Hadji-Lazaro J., Clerbaux C., Meinrat O.A., Kaiser J.W., Schulze E.D. 2013. $\mathrm{CO}_{2}$ emissions from wildfires in Siberia: FRP measurement based estimates constrained by satellite and ground based observations of co-emitted species. Geophysical Research Abstracts, 15.

Boschetti L., Roy D.P. 2009. Strategies for the fusion of satellite fire radiative power with burned area data for fire radiative energy derivation. Journal of Geophisical Research, 114, doi:10.1029/2008JD011645. 
Conard S.G., Sukhinin A.I., Stocks B.J., Cahoon D.R., Davidenko E.P., Ivanova G.A. 2002. Determining effects of area burned and fire severity on carbon cycling and emissions in Siberia. Climatic Change, 55, (1/2), 197-211.

FIRESCAN Science Team. 2013. The Bor Forest Island Fire Experiment. Part 2. In: Prescribed Burning in Russia and Neighbouring Temperate-Boreal Eurasia (ed.: J.G. Goldammer), 149-231. Global Fire Monitoring Center (GFMC) / Kessel Publishing House.

Isaev A.S., Maltseva Yu.V., Semenova V.N. 1994. Atlas of the Krasnoyarsk Krai and the Republic of Khakassia (in Russian). Roskartographiya.

Isachenko A.G. 1988. Landscapes of USSR: scale 1 : 4000000 (in Russian). Moscow: GUGK, vol. 96.

Ivanov V.A., Ivanova G.A., Moskalchenko S.A. 2011. Handbook to extinguish wildfires (in Russian). Krasnoyarsk.

Justice C.O., Giglio L., Korontzi S., Owens J., Morisette J.T., Roy D., Descloitres J., Alleaume S., Petitcolin F., Kaufman Y. 2002. The MODIS fire products. Remote Sensing of Environment, 83, 244-262.

Kaufman Y.J., Justice C.O. 1998. MODIS ATBD: Fire Products // EOS ID\#2741.

Kaufman Y.J., Kleidman R.G., King M.D. 1998. SCARB fires in the tropics: Properties and remote sensing from EOS-MODIS. Journal of Geophisical Research, 103, 31955-31968.

Konev E.V. 1977. Physical basis of vegetation fuel burning (in Russian). Nauka, Novosibirsk.

Korovin G.N., Andreev N.A. 1988. Aircraft forest protection (in Russian). Agropromizdat, Moscow.

Kumar S.S., Roy D.P., Boschetti L., Kremens R. 2011. Exploiting the power law distribution properties of satellite fire radiative power retrievals: A method to estimate fire radiative energy and biomass burned from sparse satellite observations. Journal of Geophisical Research, 116, doi:10.1029/2011JD015676.

Kurbatski N.P., Sheshukov M.A. 1978. About forest fires in Khabarovski Krai (in Russian). Lesnoe khozyaystvo, 4, 79-83.

Loupian E.A., Mazurov A.A., Flitman E.V., Ershov D.V., Korovin G.N., Novik V.P., Abushenko N.A., Altyntsev D.A., Koshelev V.V., Tashchilin S.A., Tatarnikov A.V., Csiszar I., Sukhinin A.I., Ponomarev E.I., Afonin S.V., Belov V.V., Matvienko G.G., Lo- boda T. 2006. Satellite Monitoring Of Forest Fires in Russia at Federal And Regional Levels. Mitigation and Adaptation Strategies for Global Change, 11 (1), 113-145.

Mottram G.N., Wooster M.J., Balster H., George C., Gerrard F., Beisley J. 2005. The use of MODIS-derived fire radiative power to characterize Siberian boreal forest fires. In: Proc. of the 31st international symposium on remote sensing of environment, St. Petersburg, Russia.

Nesterov V.G. 1949. Forest fire danger and methods of assessment (in Russian). Moscow, Leningrad.

Panov A., Chi X., Winderlich J., Birmili W., Lavrič J., Ponomarev E., Andreae M. 2012. Assessment of biomass burning emissions to the atmosphere from the Zotino Tall Tower Observatory (ZOTTO) in Central Siberia. Int. workshop on Impact of Climate Change on Forest and Agricultural Ecosystems and Adaptation Strategies. Siberian State University, Krasnoyarsk.

Ponomarev E.I., Valendik E.N., Kisilyakhov Y.K. 2012. Satellite Monitoring of Large Scale Wildfires in Siberia. Int. workshop on Impact of Climate Change on Forest and Agricultural Ecosystems and Adaptation Strategies. Krasnoyarsk, SFU.

Shvidenko A.Z., Shchepashchenko D.G., Vaganov E.A., Sukhinin A.I., Maksyutov Sh. Sh., McCallum I., Lakyda I.P. 2011. Impact of Wildfire in Russia between 1998-2010 on Ecosystems and the Global Carbon Budget. Doklady Earth Sciences, 441, 1678-1682.

Soja A.J., Sukhinin A.I., Cahoon Jr. D.R., Shugart H.H., Stackhouse P.W. 2004. AVHRR-derived fire frequency, distribution and area burned in Siberia. International Journal of Remote Sensing, 25 (10), 1939-1960, doi:10.1080/01431160310001609725.

Sofiev M., Vankevich R., Lanne M., Koskinen J., Kukkonen J. 2008. On integration of a Fire Assimilation System and a chemical transport model for near-real-time monitoring of the impact of wildland fires on atmospheric composition and air quality. In: Modelling, Monitoring and Management of Forest Fire (ed.: J. de la Heras et al.). WITpress, 342-351.

Stocks B.J., Hartley G.R. 1995. Fire behavior in three jack pine fuel complexes. Great Lake Forestry Center, Canada, Sault Ste. Marie, Ontario. 
Sukhinin A.I. 2008. Space Monitoring and Analysis of Catastrophic Fires in Central Siberia and Far East. North-East Asia, A la Carte, vol.19, Center For NorthEast Asian Studies. Tohoku University, 19-23.

Valendik E.N., Kosov I.V. 2008. Thermal radiation of forest fires and its impact on tree stands (in Russian). Coniferous of Boreal Zone, 25 (/2), 88-92.

Wooster M.J., Zhukov B., Oertel D. 2003. Fire radiative energy for quantitative study of biomass burning: derivation from the bird experimental satellite and comparison to modis fire products. Remote Sensing of Environment, 86, 83-107.

Yurova A.Yu., Paramonova A.V., Konovalov I.B., Kuznetsova I.N., Beekmann M. 2013. Forecast of thermal radiation and aerosol emissions from forest fires in the Central European region (in Russian). Atmosphere and Ocean Optics, 26 (3), 203-207. 